\title{
PUERMOTRICIDADE: O LINGUAGEAR LÚDICO MOTRÍCIO
}

\author{
"Puermotricidade": the Playful Language of Motricity \\ "Puermotricidade": el Linguajar Ludico Motricio
}

SÉrgio Oliveira dos SANTOS

\begin{abstract}
Resumo: Desejamos destacar nesse texto, especialmente orientado pela tríade: motricidade humana, formação de mundo e linguagens, percursos capazes de compreender as características essências das vivências da fase puer do ser humano, que vai dos primeiros contatos com a palavra, isto é, do "corpo falante”, até a fase adulescens, trajetória de ricas vivências por onde flui e frui os processos criativos e lúdicos. Trabalhamos com a pergunta: Qual é o modo de ser, de comunicar, de compreender e de agir da criança na fase puer da vida? Para responder a essa e outras questões adotamos a motricidade humana como referencial epistemológico, numa metodologia de fenomenologia-hermenêutica. $\mathrm{O}$ estudo aponta que há um modo próprio de agir do puer que entrelaça a ação, o sentido e as linguagens numa dimensão lúdico-criadora que definimos como linguagear lúdico motrício.

Palavras-chave: Motricidade humana; Jogos de si mesmo; Linguagem.
\end{abstract}

Abstract: Our wish in this text is to emphasize, especially guided by the triad: human motricity and the formation of the world and languages, capable paths for understanding the essential characteristics of the living-experiences of the human development phase that start on the first contacts with the word, which is "the speaking body" until the phase adulescens, a period of rich lifeexperiences where playful processes and creativity are lived with flow and joy. We work with the question: What is the child's way of being, to communicate, understand and to act in the puer phase of life? In order to answer this and other questions we adopt a human motricity epistemological reference in a methodology of phenomenology-hermeneutics. The study indicates that there is a proper way to act in the puer that intertwines the action, meaning and languages in a playful dimension that we define as the playful language of motricity.

Keywords: Human motricity; Oneself games; Language

Resumen: Deseamos destacar en este artículo, especialmente orientado por la tríada: motricidad humana, formación de mundo y lenguaje, caminos para la comprensión de las características esenciales de las vivencias en la fase de desarrollo humano que sigue desde sus primeros contactos con la palabra, o sea, del "cuerpo hablante", hasta una fase adulescens, la trayectoria de ricas vivencias, donde se disfrutan los procesos creativos y lúdicos. Trabajamos con la pregunta: ¿Cuál es el modo de ser, de comunicar, de actuar y de conocer en la fase puer de la vida? Para contestar a la cuestión, entre otras, adoptamos la motricidad humana como referencial epistemológico y la metodología de fenomenología-hermenéutica. El estudio apunta que hay un modo de actuar del puer que entrelaza la acción, el sentido y los lenguajes en la dimensión lúdico-creadora que nombramos el linguajar lúdico motricio. Palabras-clave: Motricidad humana; Juegos de si mismo; Lenguaje.

\section{Introdução}

A imaginação criadora de mundos, potencializando o sentido, a realização e a expressão do ser, é o solo primário para conduzir as reflexões em torno da relação da fase puer $^{1}$ com a motricidade humana ${ }^{2}$, a linguagem e a educação. Considerando que: 1) O puer é o ser que habita a mundivivência na fala, tendo na palavra um estado ampliado de possibilidades para o existir; 2) O habitar na fala situa a construção da relação corpo-mundo den-

\footnotetext{
Puer é uma designação da fase da vida proposta a partir do bispo Isidoro de Sérvilha, que vai do início da fala até a fase dos seus desdobramentos e potencializações na adolescência, ou, adulescens. Cf. Josgrilberg, 2015, p. 12. Disponível em: http://www.hottopos.com/ notand38/05-14Rui.pdf

2 A motricidade humana é um paradigma contemporâneo concebido pelo filósofo português Dr. Manuel Sérgio. A motricidade humana não é o deslocamento "físico" de um corpo. É a intencionalidade operante, é projeto, é vontade de criação, e a busca da transcendência. Cf. Trigo, 2016, p. 26.
}

tro de uma temporalidade entre o "antes" e o "depois", o que permite reflexionar a experiência corpórea; 3) O falar situa o puer para além da oralidade já que amplia as possibilidades linguísticas, ou seja, é uma corporeidade que abre-se a um outro potencial semântico de experiência criadora de mundos (práxis criadora); 4) O puer, por sua possibilidade motrícia entrelaçada com a construção de sentidos e significados ${ }^{3}$ para o agir, forma-se a si mesmo na relação com o outro de modo complicado.

Assim perguntamos: Qual é o modo de ser, de comunicar, de compreender, de vivenciar, de apropriar-se e de estruturar a motricidade-imaginação na fase puer? Como tornar as vivências educativas da fase puer um momento

\footnotetext{
Há uma importante distinção entre o "sentido" e o "significado" segundo Josgrilberg (2014, p. 20). O "sentido" aponta para uma amplitude semântica maior que a do significado. O significado é o modo como o sentido é delimitado pela língua. O sentido abrange outros campos semânticos. O significado tende aos conceitos e o sentido tende a metáfora.
} 
de ação autêntica das potencialidades humanas nas esferas narrativas e imaginativas por onde aflora a criatividade? Como o ser-motrício nessa fase pode exercitar o que compreendemos como condição de "viver fluentemente sua motricidade"? Enfim, qual é o modo de ser-motrício ${ }^{4}$ da fase puer?

O objetivo desse estudo é criar um horizonte compreensivo para a ação do ser-motrício na fase puer, que aqui denominamos de puermotricidade. Nosso referencial compreensivo preliminar é que, ao revelar a condição onto-semântico-motrícia, isto é, o entrelaçamento das múltiplas possibilidades lingüísticas do ser-motrício, é possível propor vivências educativas capazes de explorar o mundo mágico-poético que consubstancia a imaginação-criatividade do puer em ação. Para compor essas perspectivas compreensivas adotamos a fenomenologia-hermenêutica como referencial metodológico.

\section{Delimitando as problemáticas do estudo}

Deseja-se uma fenomenologia-hermenêutica da puermotricidade, vivida e manifesta nas vivências, sem desconsiderar os aportes linguísticos implicados nesse evento. Para tal percurso sugerimos a compreensão do linguagear lúdico motrício como um estado implicado da motricidade na condição onto-semântica, ou seja, uma ação humana plena de sentido e significado, vivida numa temporalidade lúdica e dedicada à apropriação de si mesmo e dos gestos específicos da cultura como, por exemplo, as vivências esportivas, as danças, os jogos, o teatro, a música, a escrita, o desenho, etc.

O termo linguagear lúdico motrício sugere a integração do conceito de linguagear proposto por Humberto Maturana Romesín e Ximena Dávila Yáñez (2009) com uma característica essencial da motricidade da fase puer radicada, e em constante busca, da ação corporal na dimensão lúdica e imaginativa de apropriação dos "modos de ser e fazer". O lúdico/a ou ludicro/a, proveniente do latim ludus, ludere, adjetivo "pertencente ou relativo ao jogo" integra o conceito apresentado. Ao propor um modo de ser do puer, estruturados e compreendidos na dimensão do linguagear lúdico motrício, ou seja, a ação de situar o ser numa confluência de intencionalidades, de certo modo, atendemos ao convite epistemológico ditado por Manuel Sérgio (1994, p. 54) ao afirmar que o que está em jogo na motricidade é "a capacidade para doar sentido ao movimento que visa à transcendência".

O sentido da ação do puer, presente num conjunto de vivências que emergem como expressão lúdica e lin-

\footnotetext{
Ser-motrício é o habitar humano na dimensão de atuação do corpo que, como singularidade e universalidade de domínio ontológico, move-se como intencionalidade do si mesmo coimplicado no mundo circundante, i.e., o estado de realização da corporeidade, onde o ser entende-se diante de si mesmo no mundo com os outros. Cf. Santos, 2017, p. 37- 48. Disponível em: http://www.hottopos.com/isle27/37-48Sergio.pdf
}

guística, se destaca como dimensão de apropriação do si mesmo e do apoderamento dos possíveis motrícios ${ }^{5}$. Assim, entendemos que só há movimento corporal humano autêntico quando o ser-motrício processa intencionalmente a relação ação-sentido-linguagens (Santos, 2014). A motricidade humana, mais que uma condição para ser definida é o próprio modo de habitar a mundivivência no corpo em ato.

Como, a partir dessa compreensão, a experiência imaginária pode ser referência para a proposição das atividades educativas na puermotricidade? É possível compreender a puermotricidade como a espaço/temporalidade do linguagear lúdico motrício? Ao abrir essa perspectiva de compreensão é possível pensar na elaboração de uma fenomenologia-hermenêutica da puermotricidade?

Essas problemáticas já indicam, por sua própria formulação, que seu mais adequado modo de tratamento vale-se de um importante pressuposto epistemológico da Ciência da Motricidade Humana, a práxis criadora. Temos na confluência criadora a possibilidade de entrelaçar a dimensão sensível com a dimensão inteligível do ser-motrício, ambos num movimento de apreensão/expressão cuja "ligação" se ordena na relação, também entrelaçada, da ação/linguagem/vida o que compreendemos como uma interação corporal de circularidade dinâmica. Numa direção, tem-se a originária condição de sentido da materialidade vivida e, como enlace, tem-se a potência da linguagem que conduz, por mediação, os horizontes da experiência para outras configurações, com seus direcionamentos vividos nas múltiplas possibilidades linguísticas. "É na práxis, ou seja, na integração de todos os saberes que melhor podemos sintetizar a unidade expressiva da pessoa humana" (Sérgio, 1999, p. 55).

A motricidade é para Manuel Sérgio (2008, p. 67) o "corpo em ato". Mas quais as essências desses atos, quais ações situadas são tipicamente autênticas da fase puer? Como tornar as vivências da espaço/temporalidade educativa da fase puer um instante de vivência autêntica das potencialidades humanas nas esferas narrativas e imaginativas onde aflora a criatividade?

A fase puer abre a possibilidade do ser para "viver fluentemente a motricidade", cuja imaginação criadora parece apontar para um modo de formação de mundo e construção de si mesmo de modo coimplicado.

A coimplicação é compreendida como ação dinâmica de comunhão do ser: consigo mesmo, com o mundo e com os outros, onde as diferenças são conduzidas por um processo de interconexão norteadora da construção das identidades singulares, situadas na pluralidade das dimensões relacionais. A coimplicação é o modo referencial que tratará do horizonte relacional interhumano,

\footnotetext{
5 O apoderamento motrício é compreendido como modo de apropriação do potencial de realização do corpo próprio, i.e., do corpo que, com as experiências, vai apoderando o si mesmo. Trata de apoderar-se de condições de ação que não tinha antes das vivências, entendidas como práxis criadora.
} 
considerando que: “...o indivíduo nunca é simplesmente um eu originariamente puro e isolado de tudo, que se experimenta a si mesmo na imanência de sua autoconsciência. É no todo de um mundo que o indivíduo vem a si” (Oliveira, 2012, p. 241).

Por exemplo, se há uma coimplicação entre a poesia e a língua, sendo essa sua expressão mais sublime, dimensão onde podemos dizer que falamos e compreendemos fluentemente as nuances de um idioma, devido sua riqueza semântica, qual é o modo de ser autêntico da motricidade humana na fase puer? Como a criança nessa fase pode exercitar e "viver fluentemente sua motricidade coimplicada"?

Nesses termos, encontramos na ludicidade esse ato poético coimplicado, um caminho de abertura para o linguagear lúdico motrício, ação de ser-no-mundo, já que, "ser-no-mundo é viver em movimento intencional, é ser corpo consciente e comunicante. A existência, através da motricidade, é um contínuo acto criativo" (Sérgio, 2008, p. 55).

Ao perguntar pelo modo de ser-motrício do puer surge entusiasticamente a perspectiva dele habitar uma mundivivência preenchida por um linguajear lúdico motrício em entrelaçamento com o linguagear motrício de apreensão/expressão, estado de práxis criadora, direção onde vamos conduzir a nossa abordagem em torno das problemáticas apontadas.

\section{Fase puer: realidades emergentes e seus desdobramentos}

Ao observar e conviver com crianças da fase puer surge para a percepção, dimensões da motricidade que encerram a própria expressão do prazer de agir diante do "curioso", onde o corpo todo parece deslocar-se como quem, sendo ele corporeidade em formação, interroga o desconhecido, um estado de emergência e implicação do que está por "realizar e formar sentidos".

O puer é curioso de sua própria condição corpórea. Por vezes o corpo puer interroga-se diante dos elementos da natureza como parte integrante desses próprios elementos, como as percepções das cores, formas, texturas, espessuras, pesos, aromas, etc. Em outras ocasiões o corpo puer deseja interrogar o "mundo curioso" dos seres vivos, i.e., dos fenômenos dinâmicos vivenciados por outros corpos, desde os pequenos insetos aos grandes mamíferos, dando a eles, sentidos existências repletos de magia. O maior encanto, atração e admiração, contudo, é o mundo humano e toda sua complexidade cultural, afetiva e lingüística.

. Esse "interrogar o mundo", pelo acesso da vivência com a materialidade corpórea, vai tornando possível a apropriação de si mesmo com os outros. O(s) mundo(s) que vai(vão) se constituindo não é(são) uma representação ipsis litteris do concreto, não se trata apenas de uma objetivação. Trata-se de um modo de acesso "modulado" por gradientes de ação entrelaçados com a imaginação, onde o puer vai sedimentando as experiências do corpo reflexivo em diálogo incessante com as dimensões semânticas da linguagem. Abre-se o mundo subjetivo, intersubjetivo e transcendente da ação humana

Nesse universo, é possível destacar os modos fascinantes e, por que não pensar, misteriosos de viver a motricidade. Na fase puer emerge um modo de existir que faz circular uma "insaciável”, necessária e permanente tarefa de edificar-se e de apropriar-se, cujo destaque recai num modo de ser que entrelaça a ação, a imaginação, a ludicidade e a multiplicidade lingüística, que confluem numa dinâmica de mundo essencialmente estruturada na coexistência ou coimplicação. A coimplicação, por sua vez, trata de revelar a importantíssima participação "do outro" como condição para a edificação do "si mesmo", possibilitando uma abertura educativa para a cocriação.

Para percorrer caminhos compreensivos que ampliem os acessos à idade da vida que corresponde ao puer, vamos abordar temas como: 1) A imaginação reprodutora e a imaginação criadora tendo a segunda como um desdobramento da mimese; 2) A motricidade, compreendida estruturalmente como um vínculo perceptivo e semântico com o mundo, pois vai mais além do simples fazer reprodutor de certo conjunto de movimentos destinados a aprimorar a funcionalidade do organismo; 3) As múltiplas potencialidades linguísticas do corpo puer em ação, que compreendemos como o linguagear lúdico motrício, i.e., um modo poético do ser puermotrício; 4) A perspectiva educativa de apreciação da natureza onto-semântico-motrícia do puer como dimensão valorativa da experiência corporal; 5) A compreensão do linguagear lúdico motrício como dimensão de formação de si mesmo com o outro, um encontro "inter-poiético" (Sérgio, 2003. p. 54), ou seja, um estado de coimplicação como "uma nova poética do possível para o ser humano em movimento" (Sérgio, 2008, p. 51). Nessa dimensão vamos explorar o processo formativo de "viver fluentemente a motricidade" pelos "corpos dialógicos e cocriadores"; 6) a perspectiva de "viver fluentemente a motricidade" não reduzida as expressões lingüística apenas sedimentadas na oralidade, mas em vários outras potencialidades e desdobramentos lingüísticos. Mais do que a fala (sendo essa considerada como radical de abertura de mundos) um modo de habitar uma mundivivência linguajante.

\section{O puer e o apoderamento motrício}

A fase puer, além de possibilitar a fala, é também a fase onde o processo de alfabetização se dá. Como apontamos anteriormente, a fala não só é uma condição de estruturação da palavra-mundo, mas uma abertura lingüística de toda a ação para o mundo com a palavra. O mesmo se dá com relação à alfabetização. A leitura não é só das palavras, mas do mundo que o puer habita no estado encarnado. Sua corporeidade lê o mundo por sua motricidade. 
Aprender a ler necessita práxis sistemática associada à desejabilidade e a intencionalidade. Assim como o puer realiza suas incursões no universo das palavras, textos e contextos, o mesmo ocorre com os movimentos corporais espontâneos e com os gestos específicos que caracterizam uma determinada vivência cultural.

Podemos dizer então que na fase puer o modo de ser-motrício também revela e circunscreve sua desejabilidade na aprendizagem e incorporação de modos específicos dos signos motrícios, i.e., da gestualidade especifica de uma praxis criadora, não apenas com a perspectiva de domínio técnico do movimento, mas na direção de apoderar-se dessa técnica (modo de fazer) como um horizonte de apreensão/expressão de sentido. "Debruçar-se" sobre os modos característicos de fazer, de compreender seus códigos, seus signos. Aqui a tarefa demanda práxis sistemática assim como no processo de alfabetização. Não há alfabetização espontânea. Alfabetizar-se é tarefa criadora assim como aprender a gestualidade específica de uma ação.

Quando o puer visa à possibilidade de constituir sua corporeidade com gestos específicos, passa a dialogar mais proximamente com a cultura na qual está situado. Parece existir muito interesse em apropriar-se dos modos específicos de agir observado nos mais velhos. Associamos isso como uma importante busca de formação de si mesmo na relação com o outro e com o lugar onde habita, que é mais do que uma localização geográfica, é um situar nas dimensões de sentido e de valor da ação.

Essa busca é fundamental para a formação da identidade do puer, de seu reconhecimento, acolhimento e organização social, bem como na sua condição de pertencimento. No que diz respeito ao ensino dos modos de ação, não há problema no exercício das possibilidades gestuais específicas para meninos e meninas na fase puer. $\mathrm{O}$ que é desaconselhável é adotar as referências do mundo dos adultos para dar sentido ao processo formativo da gestualidade das crianças. É necessário compreendê-lo como processo gradativo e permeado por instabilidades que, no transcorrer do próprio desenvolvimento, vai tomando formas esteticamente melhor estruturadas. O ser-motrício na fase puer vai edificando gradativamente seus possíveis de realização. Não há porque "acelerar” o aprendizado gestual como se observa na especialização precoce.

Por outro lado, é necessário um entendimento criterioso dos pais e educadores frente à especialização precoce da gestualidade das ações, especialmente as esportivas, visando o rendimento em competições. O aprendizado adequado respeita o processo de formação da praxis criadora, signos específicos de uma linguagem corporal culturalmente reconhecida na comunidade, valendo-se de processos valorativos que evitem as excessivas comparações produtoras de distinções excludentes. $\mathrm{O}$ processo criador é o valor primordial. Não se deve esquecer que o modo formador da gestualidade segue habitando o linguagear lúdico motrício que não é validado nas disputas competitivas em geral, e as esportivas em específico. $\mathrm{O}$ outro é referência para a constituição do si mesmo, não só por um sistema valorativo classificatório comparativo, mais especialmente pelo potencial de alteridade e coexistência implícito nas relações interhumanas das ações motrícias, ou, como tenho interpretado, como coimplicação.

Os processos valorativos das experiências motrícias na fase puer deve primar pela possibilidade constante de evoluir em seu modo de constituir, apropriar e aprimorar determinado gesto. Os eventos de fomento, nessa fase, precisam evitar as estruturas comparativas de rendimento em função da celebração coletiva do sucesso alcançado de formas distintas por todos, cada qual ao seu tempo, cada qual ao seu modo, cada qual com sua possibilidade corporal específica. Celebrar a desejabilidade de ser mais! Esse deve ser o propósito maior dos eventos de fomento do linguagear motrício formativo.

\section{A puermotricidade: a motricidade e a potência da linguagem}

A razão e a necessidade de pensar a motricidade humana entrelaçada com a linguagem na fase puer, torna-se mais evidentes no instante em que desejamos compreender o que está profundamente inserido na dimensão da materialidade vivida pela totalidade corpórea da criança, onde a experiência efetivamente se processa, "onde o genético e o cultural adquirem lugar de relevo e onde a motricidade gera símbolos" (Sérgio, s/d, p. 142). É evidente que a motricidade é um dos mais relevantes modos de expressão da criança na fase puer, já que materializa a experiência real, concreta e vivida corporalmente. Isso é notadamente perceptível no universo infantil. De fato, não é possível pensar uma fenomenologia para a fase puer sem que a motricidade seja um destaque. Entretanto a motricidade, que se destaca em concomitância com o evento da fala, inicia um caminho de sentido e de confluência criadora para as vivências até então inacessíveis. A ação do corpo, pelo poder das múltiplas linguagens, assume um caráter emergencial que transcende o fazer circunstancial.

Como ação que se pode localizar temporalmente, as experiências como a fala, a música, a corrida, a dança e o jogo - ambas pertencentes ao modo de expressão do puer - necessitam de um mecanismo que dêem duração a forma que, por sua natureza, é evanescente diante do tempo natural. O fluir e fruir da motricidade na temporalidade acaba por valer-se do mecanismo da linguagem para situar e conduzir a experiência no processo de imaginação.

Esse fluxo motrício intensamente vivenciado pela criança não pode ser ignorado. A percepção, a motricidade e a imaginação afirmam as possibilidades lingüísticas humanas. Esse processo não se estrutura de forma linear, não se trata de um curso em linha. Está mais para um modelo espiralado, esférico, numa dinâmica de circularidade, sedimentação e expansão expressiva, quase 
como um fractal, um redemoinho no fluxo do rio onde não há bordas para distingui-lo do próprio rio em fluxo (Romesin \& Yánes, 2009, p. 23).

Para exemplificar, numa simples vivência de respiração diafragmática consciente, cuja natureza é encontrar-se com o si mesmo motrício, oriento um grupo de crianças para que imaginem cenários em que possam habitar durante a proposta da vivência. Para criar uma atmosfera favorável ao ingresso mais profundo do mundo imaginário, apagamos as luzes da sala e começo a tocar a shakuhachi ${ }^{6}$. Após cerca de 4 minutos, finalizamos a experiência do relaxamento/respiração e convido as crianças a contarem os cenários imaginados. É fascinante ouvir as narrativas que apresentam, especialmente porque a ação, didaticamente sugerida, tanto considera os seus aspectos objetivos de uma materialidade vivida (respirar), como está associada ao universo da imaginação criadora de mundos possíveis para a ação. Desta descrição breve, percebemos o fluxo motrício e as possibilidades lingüísticas, entrelaçados pela própria condição de complexidade da ação do puer. Em tais vivências podemos revelar e compreender fortes vinculações entre a ação e o sentido/significado.

Há uma potência latente que deseja "viver fluentemente a motricidade", naquilo que emerge do corpo puer. Não se trata apenas de apropriar-se e utilizar isoladamente palavras ou movimentos desligados uns dos outros para viver ou descrever o que se passa com seus atos, como resultante de uma representação do mundo. Não há como o puer "viver fluentemente a motricidade" se não for dentro da relação ação-sentido-linguagens e, especialmente a imaginação formadora de mundos, já que: "nos mais diversos contextos, a motricidade aparece como manifestação do homem como linguagem e como diálogo" (Sérgio, 1981, p. 127).

Quando pensamos na mais suprema forma de expressão da língua bem possivelmente vamos nos deparar com a poesia. A poesia tem clara forma estrutural e um potencial semântico que se estende de forma ilimitada devido à abertura ao mundo imaginário. Se pensarmos em "viver fluentemente a motricidade" o que teremos como referência? Como essa condição se manifestaria? De que maneira podemos propor modos refinados de expressão motrícia humana nas vivências educativas da fase puer? Essa reflexão é fundamental para se pensar a educação, bem como para compreender a motricidade humana e sua relação com a linguagem, especialmente para reforçar e defender a tese de que, na fase puer, há uma corporeidade integrada e integradora que se manifesta expressivamente, não somente como oralidade/escrita ou como raciocínio que manifesta uma equivocada e reduzida explicação por “representação" da realidade.

A dinâmica motrícia, i.e., o fazer, flui melhor quanto mais e melhor é vivenciado. A desejabilidade de agir é marcante na fase puer tornando evidente sua função de

\footnotetext{
${ }^{6}$ Flauta japonesa de 5 furos.
}

apropriação do si mesmo em estado coimplicado como o outro e o encontro com seus possíveis de realização. Esse "agir" permite sim que a ação se torne mais eficiente, já que as estruturas biodinâmicas do movimento corpóreo são aperfeiçoadas, isso é fato. Porém, esse "agir" do puer não é o que demarca seu ímpeto volitivo, que não pode ser reduzidamente compreendido como gasto de energia despropositada, como alguns educadores gostam de afirmar. Não há esse tipo de desejabilidade na fase puer. A puermotricidade reflete a apropriação de si, assim como um apoderamento do "eu posso", e de um "eu sou”, pois "quando movo me sinto". Não se trata de uma representação mental do si mesmo, trata-se de um si mesmo que entra em ação com o mundo, apodera-se pelo ato criador que entrelaça a motricidade com a imaginação/linguagem, são "jogos de si mesmo", condição muito distinta de apenas considerar a ação do puer um "gasto de energia" ou um "condicionamento físico".

É relevante destacar, especialmente do ponto de vista educativo, que a práxis sistemática de um movimento não garante a exploração da dimensão poética dos "jogos de si mesmo", onde se revela a dimensão imaginativa e criadora da ação do puer. A habilidade de executar um movimento pode ser "treinada" por uma "prática”, já o sentido, os valores e os modos relacionais de uma ação, próprios da criação humana (vivências essenciais para a formação do puer), não se compõem por essa metodologia. A vivência sistemática, regulada, intencional e situada culturalmente será edificada autenticamente se estiver vinculada a um sentido-significado, abrindo assim condições para uma narratividade. É nessa constante busca de narrar suas potencialidades motrícias, é nesse curso ininterrupto de agir e imaginar, que se forma o discurso do corpo em ato, que suplanta os condicionantes biológicos ou uma isolada perspectiva do desenvolvimento motor e as explicações psicológicas, para adentrar e existir numa constante condição constitutiva e transcendente do puer. O puer-motrício pode, a partir daí, ser interpretado como ser-de-linguagens, possibilidade de ser que compreendo como:

[...] o humano que se move de forma autoconsciente numa corporeidade em ato cuja intencionalidade volta-se para o mundo circundante, ação de abertura e permanente construção de possibilidades na condição do ser-no-mundo, uma condição de múltiplas linguagens vividas em múltiplos sentidos. (Santos, 2014, p. 106)

Portanto, é na condição de ser-motrício que vislumbro a possibilidade do puer "viver fluentemente a motricidade", uma compreensão que revela um modo de existir na ação. Não se trata apenas de compreender as crianças como executores de movimentos que simplesmente marcam o tempo e que respondem a certas fases do desenvolvimento biodinâmico, mas que possam existir e viver no 
tempo dimensionado, não apenas por estruturas que possam ser aferidas, mas especialmente por aquelas que possam ser imaginadas e vividas em plenitude de realização.

Sendo essa sua essência, a criança puer é a expressão autêntica da motricidade. Só deixará de ser, em sua ampla compreensão, por força da fragmentação imperiosa que reduz as percepções da ação pelas explicações isoladas do racionalismo. Essa epistemologia obstrui, de certo modo, o fluir da unidade fenomenológica do puer-motrício. A orientação fenomenológico-hermenêutica que estamos tratando, ao complementar-se com outras abordagens empíricas, abre possibilidades de formar um olhar diferenciado diante do modo de ser-motrício do puer, estimulando e reorganizando a compreensão de suas experiências motrícias com a linguagem.

Para essa questão, Manuel Sérgio tem fornecido um importante suporte para aprofundar as relações da motricidade humana com a linguagem, como podemos constatar a seguir:

É pela cultura, a sua autêntica segunda natureza, que o ser humano adapta o meio às suas necessidades. Ser carente - ser práxico, mas ser práxico porque dotado de inteligência inventiva e de linguagem. A sua praxis descerra um mundo de possibilidades, que o animal não alcança (Sérgio, s/d, p. 46).

Como a apropriação da linguagem é uma das marcantes características da fase puer, a imaginação nela circunscrita consubstancia o modo de mover o corpo numa dimensão que não se explica apenas no movimentar de um corpo-objeto de um local para outro. A motricidade da criança não se reduz à interpretação de deslocamento de um corpo no espaço-tempo ${ }^{7}$. O puer-motrício orienta-se em direção às coisas e aos outros e, em tais direcionamentos, mais do que simples deslocamentos, abre-se em leque de sentidos, significados, valores e relações que projetam um mundo de distintas possibilidades existenciais e expressivas, assim "os movimentos corporais, como projeto, dão sentido ao próprio espaço” (Sérgio, s/d, p. 63).

O projetar-se do puer-motrício é revelador de que seu sentido de ação não é a "performance”, como o adulto dimensiona, é a apropriação do si mesmo coimplicado, conjunto de experiências capazes de modular a identidade pelas narrativas próprias do mundo da imaginação especialmente vividos como um jogo, um dimensionamento lúdico da ação. É nessa dimensão que o puer põe-se em totalidade no ato.

\footnotetext{
Como se pode observar na série de vídeos na internet que promovem a divulgação de "treino funcional" para crianças, uma espécie de circuito de exercício que é denominado de crossfit kids. Veja alguns exemplos do que problematizamos nesse estudo em: https://www.youtube.com/ watch?v=OHbwttWkv48 - https://www.youtube.com/watch?v=L6P-NJNlUbA - https://www.youtube.com/watch?v=X29DdCt2G0U - ht tps://www.youtube.com/watch?v=l6hUMDbphSc. Último acesso em: 13/11/2016.
}

\section{Puermotricidade: o falante no linguagear lúdico motrício}

O que queremos nesse estudo, entre tantos aspectos, é destacar a relação entre a motricidade, a ludicidade e a imaginação, tomados ambos como potencializadores uns dos outros. De fato, creio não ser possível dissociá-los, particularmente quando surge a dimensão da linguagem. $\mathrm{O}$ essencial é reconhecer que esses elementos caracterizam a fase puer, e que os sentidos e valores que estão vinculados à ação sejam observados.

A linguagem do discurso lúdico motrício tem como essência o rompimento com o real, i.e., com o mundo objetivado e com o estado cotidiano da linguagem ordinária sem evidentemente desconsiderá-la. Além disso, tal "ruptura" permite um reescrever a realidade adentrando nas esferas subjetivas, intersubjetivas e transcendentes da ação humana. O discurso lúdico motrício é um estado de metáfora viva do corpo de ordem dinâmica e multilinguística que alimenta a imaginação criadora. Isso porque, ao perturbar a ordem lógica existente no cotidiano é capaz de gerar outra gama de sentidos-significados. Essa dimensão é o que se vivencia no jogo. O jogo é a linguagem autêntica do mundo puer ${ }^{8}$.

A imaginação criadora participa ativamente na (re) descrição do real cujos sentidos criados nos permite compreender a realidade como hipótese, assim, a imaginação possui a função de construção e reinterpretação do real e, por conta disso, produtora de sentido. Isso se dá exatamente pela utilização metafórica da linguagem presente no linguagear lúdico motrício.

O linguagear lúdico motrício, uma das características essenciais da fase puer, é o espaço/temporalidade das experimentações das múltiplas intencionalidades, em múltiplas linguagens e em múltiplos sentidos onde a criança pode "exercitar-se a si mesmo" na relação com o ambiente e com o outro, e não somente exercitar o corpo biodinâmico para desenvolvimento de desempenho motor. Toda a função biodinâmica do corpo puer pode ser autenticamente estimulada se o conjunto das experiências motrícias estiver circunscrita na atmosfera da ludicidade, do jogo e das narrativas que explorem a imaginação criadora. A motricidade, como práxis corpórea, permite o desenvolvimento de processos lúdicos-criativos-linguajantes formadores do si mesmo, dos modos relacionais e dos espaços de vida onde interatuam os humanos.

Os desdobramentos fenomenológicos apontados sugerem que o modo de habitar a práxis do linguagear lúdico motrício precisa projetar: 1) A imaginação criadora e reprodutora, compreendidas como um desdobramento da mimese; 2) As vivências dialógicas como modo de constituir-se na naturalidade das diferenças; 3) As relações afetuosas, fraternas e cordiais; 4) A organização situada na motivação, na vontade de participar, pertencer e perceber

\footnotetext{
8 Cf. Santos, 2015, p. 47-60. Disponível em: http://hottopos.com/ notand38/47-60Sergio.pdf
} 
as experiências motrícias como horizonte para formar-se a si mesmo com o outro; 5) Os estados valorativos que configurem o referencial da coimplicação, superando os modos classificatórios dualistas para caminhar na direção dos modos dialógicos de convivência; 6) A exploração de múltiplas linguagens e dos múltiplos sentidos; 7) A diversão, o riso, a alegria, o prazer de estar juntos; 8) Processos valorativos das experiências motrícias como celebração coletiva do sucesso alcançado de formas distintas por todos, cada qual ao seu tempo, cada qual ao seu modo, cada qual com sua possibilidade corporal específica; 9) Um sentido para ação que transbordem o fazer pelo fazer, somente vinculado à "performance motora" e transforme-se numa "potencialização e apoderamento motrício" que considere, de forma inerente, a ludicidade, a imaginação e as narrativas próprias do jogo.

Esse modo de habitar o si mesmo parece condizente com a definição de re-creação proposta por Trigo (2015, p. 98): "Rama de la motricidad humana, que pretende el desenvolvimiento de procesos lúdico-creadores-corpóreos de cara a la tranformación-enrequecimiento de si mismo, de las comunidades y de los espacios de vida en dónde interactúan los seres humanos".

A educação motrícia na fase puer, e seus agentes formadores, tem nessas reflexões um estímulo para retomar o solo originário do sentido da ação da criança. Que o dimensionamento desse fenômeno permita compreender, interpretar e apreciar o universo do linguagear lúdico motrício.

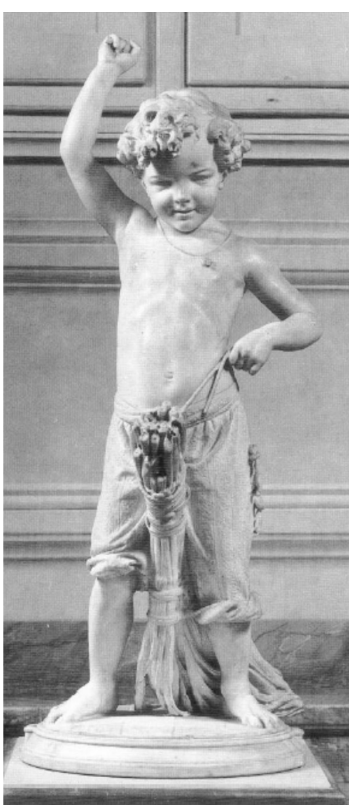

Ilustração 1: Fanciullo a Cavallo di una scopa, 1875. Francesco Barzaghi (18391892) Milano. Obra exposta no palácio Pitti - Florença.

Na Ilustração 1, por exemplo, observamos uma obra que revela o diálogo entre linguagem, imaginação, ludicidade e motricidade. Assim, referenciamos a compreensão da essência motrícia do puer e do modo como a linguagem potencializa a ludicidade/imaginação da criança. A motricidade situada, ou seja, estado entrelaçado de ação-sentido-linguagem, transgride uma condição espaço-temporal sujeita a mensurações (como já apontamos) para ampliar os horizontes do habitar humano. A relação motricidade-imaginação, observada na ilustração acima, conduz o puer a viver numa outra temporalidade.

A vida autêntica num instante lúdico provoca um recorte no tempo cotidiano, aquele em que tudo parece matematicamente organizado e estruturado, onde os fenômenos podem ser mensurados e controlados. A vida autêntica num instante lúdico reorganiza e apresenta outra temporalidade já que suprime o tempo do cotidiano. Mesmo que o jogo e a brincadeira necessitem certo tempo e espaço para acontecer e, mesmo que tenham regras e estruturas rígidas de organização, o tempo para o jogador ou para o brincante que está entregue na atividade não é o mesmo daquele que percorre e ocupa a vida fora dele (Santos, 2015, p. 50).

No jogo, na imaginação e nas narrativas da fase puer, assim como nas intersecções entre fantasia e realidade, sejam elas orais, gráficas, sonoras e/ou motrícias, as vivências são prontamente tarefas potencializadoras da formação de si mesmo, uma jornada na busca da individuação, o devir do si mesmo, pois a existência é uma tarefa a realizar. "Ser humanamente é agir para ser mais" (Sérgio, s/d, p. 71). E, nesse caminhar, o ser vai constituindo sua identidade.

O exercício de se (re)encontrar em si mesmo se dá na relação com o outro, ou seja, nas redes relacionais objetivas e intersubjetivas. A cultura educadora deve estar muito atenta a esses modos relacionais, assunto que discutiremos mais adiante ao tratarmos dos corpos dialógicos e cocriadores da fase puer e a construção da alteridade.

O puer é o "corpo-falante” no linguagear lúdico motrício. Alguns povos parecem intuir isso ao proporem maneiras de representar essa essência pela linguagem. Por exemplo, a maneira como o ideograma japonês Asobu localiza o jogar é muito interessante e vale a pena destacá-lo nesse estudo. A interpretação sugere que o jogar-brincar é "a direção pela qual a criança caminha”. É notável a condição implicada do ser criança com a linguagem que a define.

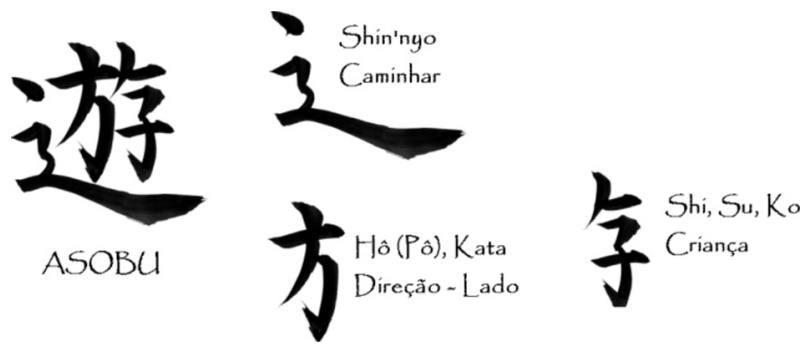

Asobu significa: "Jogar, divertir-se. Jogo em geral, recreação, relaxamento, divertimento, passatempo, excursão ou passeio, distração, deboche, preguiçar, ócio, disponibilidade. Significa igualmente jogar alguma coisa, representar, imitar" (Huizinga, 2012, p. 39-40). 
A idade mágica da fase puer situa a motricidade numa dimensão lingüística essencialmente poética, pois cria um modo de vivenciar e compreender a realidade baseados no encanto e na admiração de eventos simples, porém, desencadeadores de universos imaginativos ilimitados. Esse potencial característico da fase puer é um forte componente do estado consciente volitivo da ação norteadores da intencionalidade, e devem ser considerados e aproveitados na construção de experiências educativas coerentes.

Sobre o linguagear, terminologia que aprendemos com Humberto Maturana, especialmente por propor um estado de ação-linguagem entrelaçados ao torná-la verbo, é um recurso da língua que pode nos ajudar a compreender aquilo que torna a fase puer uma "corporeidade falante".

Como seres humanos, vivemos imersos em um fluir incessante de ações que Maturana chama de "linguagear”. A linguagem é usualmente entendida como a transmissão de informação simbólica. Mas, em seu trabalho, Maturana deixa o conceito de informação completamente de fora; diz que os símbolos são secundários ao ato de linguagear, que é essa coordenação de condutas. Então, o linguagear é um modo de viver caracteristicamente humano, no qual somos imersos desde crianças. Em nossa educação, aprendemos e nos transformamos nessa coordenação de condutas com outros seres humanos. Eu consigo, eventualmente, coordenar condutas e coordenar coordenações de condutas com o meu cachorro. Mas o meu cão não vive em coordenação de condutas; ele não vive na linguagem; ele não linguageia com outros cães. Mas eu vivo fazendo isso que estou fazendo agora, continuamente. Todos nós fazemos isso. Só somos humanos porque participamos desse tipo de atividade (Vaz, 2008, p. 65).

Diante do exposto consideramos a fase puer um modo de ser-no-mundo, vivido no linguagear lúdico motrício, um marco por onde transita a imaginação e a relação com muitos mundos possíveis a partir dos jogos de si mesmo em direção a conquista da autonomia, estruturada no crescente descentramento exercitado nos modos relacionais intersubjetivos.

Manuel Sérgio (s/d, p. 156) compreende que “...jogo não é uma fase, mas uma dimensão da própria vida, que gera a cultura, a arte o desporto, sob um clima de improdutividade, liberdade e festa”. Para Eugênia Trigo (1999, p. 89) a ludomotricidade diz respeito às ações provenientes de atividades que o ser humano realiza sem nenhum fim fora dele mesmo. Está mais próximo da teoria do ócio e, portanto não tem propósito utilitário. A ludomotricidade puer, ou, puermotricidade, vivida no linguagear lúdico motrício, não é só um evento de fabulação, espaço-tempo para dar asas à imaginação, mas é a dimensão para o apoderamento de si mesmo na relação com o outro como veremos a seguir.

\section{O linguagear lúdico motrício como espaço/ temporalidade da expressão da alteridade}

Adotando o linguagear lúdico motrício como modo de relação comunicativa numa experiência educativa, abrimos um caminho pra refletir sobre os corpos que dialogam, já que esses passam a ser o foco do aprendizado.

Um ser-motrício cocriador é aquele que se abre para ação consigo próprio, com outros corpos e com o universo objetivo, subjetivo, intersubjetivo e transcendente, permeando suas experiências com o mundo. Vale ressaltar que isso se dá em diferentes níveis e em distintas etapas da vida, de acordo com os diferentes corpos que existem. No caso desse estudo em particular, procuramos compreendê-lo na fase puer. A composição das corporeidades cocriadoras se dá, pela compreensão fenomenológica, como uma permeabilidade de espectros que não deveriam referenciar somente as "deficiências", mais todos os seres humanos em todas as suas potencialidades.

Uma experiência educativa autêntica, na direção da alteridade, corresponde a espaço/temporalidade das corporeidades cocriadoras numa dinâmica de encontro, por vezes materializadas em jogos de disputa, onde as diferenças são conduzidas por um processo de harmonização norteadora da construção das identidades individuais e coletivas, onde é possível exercitar o diálogo incessante da singularidade e da pluralidade dos modos de ser, não somente aquelas diferenciações dos dados coletados por mensuração, posteriormente classificados e comparados, mas das experiências de vida que podem ser narradas. Pensar em organizar uma experiência educativa onde as possibilidades motrícias cocriadoras sejam foco é um significativo avanço, porém, construir e colocar em ação um projeto de vivências formativas dentro dessa perspectiva é desafiante mas, é possível.

A proposta de vivências educativas, subsidiadas pelo conceito da corporeidade cocriadora, torna "experienciável” a intersubjetividade. As ações inspiradas por vivências educativas coimplicadas, onde corpos dialogam com suas diferenças, já que habitam o linguagear lúdico motrício na tentativa de "viver fluentemente a motricidade", devem ser mais "ouvidas" na praxis educativa. No entanto, quem as "ouve"?

O convite aos educadores é olhar o puer nos modos relacionais das distintas vivências, analisando o convívio interhumano e as implicações dessas experiências compartilhadas na construção da identidade, do pertencimento e do reconhecimento. A dimensão física e objetiva da corporeidade, sem desconsiderá-la, é assim transbordada para a dimensão do puermotrício, uma superação da "educação do físico" para a "educação do ser-motrício".

Assim, a educação do ser-motrício faz o puer pertencer a um modo de ser cujo valor permite formar sentidos e significados para o próprio existir em seu mundo e no mundo com o outro, um modo de exercitar os jogos de si mesmo. Somos corpo e, ser corpo, tem relação com tudo 
que diz respeito ao sentido de ser humano. É fundamental romper as barreiras dos dualismos e a supervalorização do racionalismo em direção a uma experiência educativa cuja gênese é a ação humana autêntica no sentido da coimplicação.

Um caminho, entre possíveis, é a adoção da puermotricidade como referência para tratar as diferenças, olhar o olhar do outro e os encontros dos modos de ser. Os corpos-falantes do puer são distintos em muitos aspectos. $\mathrm{O}$ ato de ensinar a olhar/ouvir essa condição natural da existência é revelador para compreender as distintas formas de ser. O olhar/ouvir a que me refiro é mais amplo, em sentido, do que o ato de ver/escutar como fenômeno físico. O olhar/ouvir é o contato do ser com o seu entorno cujos sentidos dos órgãos sensoriais da experiência transportam-se pelos sentidos próprios da linguagem humana, cuja capacidade de (re)criar a realidade é a essência. Se nos apropriarmos dessa ontológica condição humana vamos compreender que, como extensão a essas características, os modos de interagir com o mundo, com os outros e consigo mesmo seguem o mesmo princípio das distinções visíveis no corpo-manifesto.

Nos corpos-falantes do puer, diferentes seres habitam diferentes mundos construídos por onde circulam diferentes sentidos desse mundo horizonte em que juntos habitamos. A educação do ser-motrício, portanto, precisa fazer emergir as essências imanentes dos corpos para o transcendente cultural que considere a coimplicação, ampliando assim, possibilidades de existir, revelando dimensões do corpo-próprio, para que, a partir daí, possamos movê-lo, vê-lo, ouvi-lo, senti-lo, compreendê-lo e apreciá-lo.

A contradição educativa que se observa está na dimensão cultural de uma sociedade ocupada em promover a inclusão, pois, a partir do momento que se fala em inclusão, fica implícita a desconsideração das diferenças na corporeidade como condição ontológica do humano, de certo modo, nega-se, de princípio, a coimplicação e o entrelaçamento de distintos gradientes de possíveis de ação. Estamos, portanto, vivendo o paradoxo da inclusão numa sociedade classificatória. Se a coimplicação fosse princípio, não seria necessário falar de inclusão e sim de modos dialógicos dos distintos gradientes motrícios e seus distintos sentidos de mundo e existência. Esse é um pensamento muito pertinente quando falamos na formação de seres que estão construindo o si mesmo na relação com o outro, característica destacável na fase puer.

O que se observa é uma demanda de investimento em metodologias preocupadas em comparar as diferenças com o propósito de classificar as crianças puer a partir de escalas. As distinções das potencialidades humanas nas suas relações sujeito-objeto, sujeito-sujeito e sujeito-mundo vividos na fase puer devem, segundo o princípio da coimplicação, superar os modos classificatórios para caminhar na direção dos modos dialógicos e cocriadores, consubstancialmente narrativos, já que, toda vida da criança a partir da fase puer é interdiscursiva.
Trata-se de uma mudança de paradigma que encontra na fenomenologia-hermenêutica da motricidade uma orientação para (re)orientar as relações interhumanas. Cabe perguntar: Porque a humanidade tem tanta dificuldade em reconhecer a coimplicação entre os seres humanos? Quais desdobramentos e ressonâncias poderiam surgir em uma educação pronta para considerar a puermotricidade como horizonte formativo das corporeidades cocriadoras?

Os processos comparativos das "performances motrícias” das crianças fortalece os processos de dominação e de poder e, por ele são alimentados. Estrutura-se ai um ciclo de desigualdades nos espaços educativos da fase puer. Na atualidade, além da demarcação potente das vivências, esses componentes estão fortemente representados na esfera simbólica e na esfera da linguagem, e pouco apresenta possibilidades de diálogos que vislumbrem a potencialização da alteridade. Sustenta-se, no modo classificatório, a eliminação do diferente e o enaltecimento do "potente" que, de modo eficaz, atende a um tipo específico de processo valorativo.

O esporte em particular, e as demais ações em geral, como manifestação motrícia das crianças, possuem uma exemplar condição material e simbólica da formação humana. Por que razão os espaços formativos dessas vivências oferecem apenas um caminho único de processo valorativo, notadamente assentado num modo representativo do estado comparativo que visa à classificação por escalas de habilidades válidas e inválidas, onde muitos meninos e meninas da fase puer são submetidos? Não há outros modos de valorar a puermotricidade? Não somos capazes de criar outras referências?

O desafio é avançar da condição de valorar a puermotricidade das distinções comparativo-classificatórias para avançar na direção da coimplicação motrícia. Se estendermos essa condição para o campo da ontologia, em especial na condição de ser-no-mundo e na formação dos mundos, vamos direcionar e compreender as atividades educativas não como um processo de formatação de "condutas motoras" a partir de escalas de classificação, mais um processo de estabelecimento de diálogo com os muitos mundos motrícios. A educação da puermotricidade prevê, nessa perspectiva, a espaço/temporalidade do diálogo desses muitos mundos, um exercício dos corpos dialógicos do si mesmo coimplicado e não somente um treino funcional para crianças. Quando propomos situar e puermotricidade no linguagear lúdico motrício, rompemos com os modelos restritos de experiência educativa para adentrarmos no autêntico modo de "viver fluentemente a motricidade", um modelo libertador, expressivo, afetuoso, solidário, criativo, técnico, estético, ético e, sobretudo político social.

No linguagear lúdico motrício é possível formar a intersubjetividade narrativa dos corpos cocriadores, um espaço/temporalidade para a construção social da pessoa nos planos da observação recíproca, interpenetração e co- 
evolução (Sérgio, 2003, p. 54), uma práxis hermenêutica que convida o puer ao diálogo, ao encontro. Uma espaço/temporalidade no qual se torna possível a concretude das relações com o diferente, pois: "A intersubjectividade pressupõe a diferença (a diferença das várias subjectividades que a compõem)" (Sérgio, 2003, p. 54). Por isso retomamos o linguagear lúdico motrício como momento da construção da alteridade, compreendendo que somos seres profundamente outrodependentes.

A alteridade pode ser tomada como uma das essências do linguajear lúdico motrício se o educador, consciente dessa dimensão, direcionar as vivências corporais nesse sentido. Assim, a puermotricidade pode ser um linguagear lúdico motrício da coexistência e da cocriação, onde a disputa no jogo é o exercício pleno do encontro.

\section{Considerações finais}

Na instigante tarefa investigativa de compreender as formas de manifestação motrícias da fase puer, situando o ser-motrício entrelaçado com a linguagem, procurou-se desvelar e situar a essência volitiva do gesto lúdico espontâneo e do apoderamento do si mesmo pelo saberfazer cultural nos valores humanos veiculados nessas vivências. Podemos destacar que o modo próprio de ser-motrício da criança da fase puer evidencia as seguintes compreensões:

- A motricidade humana é uma referencia epistemológica de grande relevância para a compreensão das fases da vida, nesse texto ressaltando a fase puer;

- A linha investigativa pela fenomenologia-hermenêutica aponta duas grandes dimensões no modo de ser-motrício da fase puer: 1) Uma apropriação de si mesmo de modo coimplicado e 2) Um apoderamento dos possíveis de ação;

- O ser-motrício na fase puer move-se num entrelaçamento de ação-sentido-linguagens, que neste estudo compreendemos como fenômeno do linguagear lúdico motrício;

- Que o puer vive "fluentemente sua motricidade" se habitar plenamente a dimensão de atuação lúdico criadora, ou seja, a práxis criadora. Não se trata de vivência centradas num si mesmo isolado, mas, precisamente, num si mesmo coimplicado, ou seja, coexistente;

- As vivências dos possíveis de ação do puer, ou seja, a puermotricidade, são significativas para a formação da identidade e do pertencimento. Por isso é muito importante considerar como a educação organiza os processos valorativos das ações;

Se esses distintos, porém complementares modos da puermotricidade forem referência para as propostas educativas, em ambos os casos, envoltos na dimensão criativa e imaginativa, tanto melhor será a contribuição formativa para esses seres.

\section{Referências bibliográficas}

Huizinga, J. (2012). Homo ludens: o jogo como elemento da cultura. São Paulo: Perspectiva.

Josgrilberg, R. (2014). O mito, uma interpretação metafórica. In: R. Josgrilberg \& J. Lauand, Estudos em antropologia e Linguagem. São Paulo: Factasch Editora.

Oliveira, M. A. (2012). Antropologia filosófica contemporânea: subjetividade e inversão teórica. São Paulo: Paulus.

Romesín, H. M. \& Yánez, X. D. (2009). Habitar humano: seis ensaios de biologia-cultural. São Paulo: Palas Athena.

Santos, S. O. (2015). Infância e motricidade: vida autêntica num instante lúdico. Revista Notandum (Porto/ São Paulo), XVIII (38), p. 47-60.

Santos, S. O. (2014). Ação, sentido e linguagem: essência da motricidade humana. Revista internacional d'Humanitats (Barcelona/São Paulo), 31, p. 103-114.

Sérgio, M. (s/d). Para uma epistemologia da motricidade humana: prolegómenos a uma nova ciência do homem. Lisboa: Compendium.

Sérgio, M. (2008). Textos Insólitos. Lisboa: Instituto Piaget.

Sérgio, M. (1999). Um corte epistemológico. Da educação física à motricidade humana. Lisboa: Ed Instituto Piaget.

Sérgio, M. (2003). Alguns olhares sobre o corpo. Lisboa: Instituto Piaget.

Sérgio, M. (1994). Motricidade humana: contribuições para um paradigma emergente. Lisboa: Instituto Piaget.

Sérgio, M. (1981). Filosofia das actividades corporais. Lisboa: Compendium.

Trigo, E. (Org.) (1999). Creatividad y motricidad. Barcelona: INDE Publicaciones.

Trigo, E. (2015). Motricidad Humana: aportes a la educación física, la recreación y el deporte. España-Colombia: Instituto Internacional del Saber Kon-Traste.

Trigo, E. (2016). De la motricidad humana al paradigma vida. Espanã-Colómbia: Instituto Internacional del Saber Kon-traste.

Vaz, N. M. (2008). O linguagear é o modo de vida que nos tornou humanos. Cienc. Cult. [online]. 60 (Nr. Especial), p. 62-67.

Sérgio Oliveira dos Santos - Doutor e Mestre em Educação pela Universidade Metodista de São Paulo (UMESP), Licenciado em Educação Física pela Escola Superior de Educação Física de São Caetano do Sul. Professor de Educação Física e Judô da Prefeitura Municipal de São Caetano do Sul. Membro fundador da REMoHC - Rede Educativa de Motricidade Humana e Corporeidade.E-mail: sergio_oliveirasantos@hotmail.com

Recebido em 14.02.17 Primeira Decisão Editorial em 25.05.17 Aceito em 22.06.17 